\title{
Indicadores de sustentabilidade geram planos de melhorias em propriedade rural
}

Sustainability Indicator generating improvement plans in farm

Tulio Ibanez Nunes ${ }^{1}$; Daiane Aparecida Fausto ${ }^{2}$

${ }^{1}$ Rio Corrente Agropastoril SA - Sócio Proprietário - Rua Vivaldo Guimarães, 15-55, sexto andar conj. 61 - CEP 17012-120 - Bauru (SP), Brasil

2 PECEGE - Associada profissional - Rua Alexandre Herculano, 120 Sala T6 - CEP 13418-445 - Piracicaba (SP), Brasil

\section{Resumo}

O diagnóstico de sustentabilidade de uma propriedade deve seguir um conjunto de métodos bem definidos e padronizados para que esta avaliação seja completa e válida. O objetivo do trabalho foi realizar um diagnóstico utilizando o programa de Avaliação Ponderada de Impacto Ambiental de Atividades do Novo Rural [APOIA-NovoRural], ferramenta desenvolvida pela Embrapa. Além de fazer o diagnóstico detalhado das dimensões da sustentabilidade também foram propostas melhorias nos pontos fracos identificados pelo método. A identificação dos pontos fracos está diretamente associada a baixos escores no método APOIANovoRural. Uma análise detalhada das causas de baixos escores foi realizada e posteriormente foram identificadas possíveis melhorias. Sistemas de produção integrados como: integração lavoura pecuária, integração lavoura pecuária floresta e Silvipastoril foram analisados e serviram de base para proposta de aumento da sustentabilidade nas dimensões ambiental e econômica. $\mathrm{Na}$ dimensão social, um estudo de melhoria de condições de saúde dos colaboradores foi apresentado. Um plano de melhoria tipo Plan, Do, Check, Action [PDCA] foi construído para implementação de um sistema silvipastoril, e um para a área de saúde ocupacional. $\mathrm{Na}$ análise de sustentabilidade, realizada pelo programa APOIA-NovoRural, foi possível identificar os pontos fracos e com a implantação de ciclos PDCA ter um sistema de melhoria contínua.

Palavras-chave: APOIA-NovoRural, Cerrado, PDCA, Pecuária de Corte, Silvipastoril

\begin{abstract}
The diagnosis of sustainability in a farm must follow a set of well-defined and standardized methods for this evaluation to be complete and valid. The aim of this paper is to make a diagnosis using a tool developed by Embrapa called APOIA-NovoRural method. Besides of making a detailed diagnosis of the sustainability dimensions, improvements were also proposed in the weaknesses identified by the method. The identification of weaknesses is directly associated with low scores in the method APOIA-NovoRural. A detailed analysis of the causes of low scores was performed and later possible improvements were identified. Integrated production systems such as: integrating livestock farming, integrating cattle ranching and Silvipastoril were analyzed and served as a basis for increasing sustainability in the environmental and economic dimensions. In the social dimension, a study to improve the health conditions of employees was presented. A improvement plan like Plan, Do, Check, Action [PDCA] was built for the implementation of a Silvipastoril system, and an improvement plan in the occupational health area. In the sustainability analysis carried out by the APOIA-NovoRural, it was possible to identify weaknesses and with the implementation of PDCA cycles we have a continuous improvement system.
\end{abstract}

Keywords: Beef cattle, Cerrado, APOIA-NovoRural, PDCA, Silvipastoril

\section{Introdução}

No Brasil, no estado do Mato Grosso do Sul, a pecuária de corte tem passado por um processo de evolução nos últimos anos, de uma pecuária pouco eficiente e de pouca gestão para um modelo tecnificado e com gestão profissional. Neste contexto, a sustentabilidade tem papel fundamental, pois aborda os três pilares base: o econômico, o social e o ambiental (Simões e Moura, 2006; Rodrigues et al., 2010).
A produção de bovinos de corte é responsável por 70\% das emissões de CH4 (MCTI, 2010). O Brasil possui o segundo maior rebanho de carne bovina do mundo, com mais de 200 milhões de animais de acordo com o Instituto Brasileiro de Geografia e Estatística (IBGE, 2013). Dessa forma, é necessário que produtores envolvidos na produção de gado de corte atuem no desenvolvimento da pecuária sustentável. De modo geral, o sistema de produção de carne no Brasil é realizado em sistema extensivo, normalmente em solos de baixa produtividade, com problemas associados à fertilidade natural, acidez, topografia e limitações de 
drenagem, que podem gerar índices de baixa produtividade no sistema (Pereira, 2015) ${ }^{1}$.

Iniciativas de planos como Agricultura de Baixo Carbono, redução da emissão de gás metano pelos animais, programas como selo de Boi Carbono Zero da Empresa Brasileira de Pesquisa Agropecuária [Embrapa] demonstram a importância do desenvolvimento sustentável para a pecuária (Alves et al., 2015). De um lado existe a pressão por demandas ambientais e sociais (Kuzma et al., 2015), principalmente devido à escassez de recursos naturais e ao aumento da poluição. No entanto, é imprescindível o alinhamento da sustentabilidade com a rentabilidade do negócio, pois é a geração de renda que torna viável as práticas sustentáveis (Kuzma et al., 2015).

Diante do exposto, com o intuito de apresentar propostas e planos de melhorias nos três pilares da sustentabilidade: o social, o ambiental e o econômico, objetivou-se avaliar os indicadores de sustentabilidade em uma propriedade rural em que predomina o bioma cerrado.

\section{Material e Métodos}

O trabalho foi realizado em uma propriedade rural localizada no município de Coxim, no Mato Grosso do Sul, Brasil. Para avaliação dos indicadores de sustentabilidade foi utilizado o programa de Avaliação Ponderada de Impacto Ambiental de Atividades do Novo Rural [APOIA-NovoRural] da Embrapa, para o levantamento dos pontos a serem melhorados. Após a análise dos resultados foi elaborado um conjunto de planos de melhoria utilizando-se da técnica Plan, Do, Check e Act [PDCA]. Estes planos geraram roteiros que foram usados na implantação das melhorias. O APOIANovoRural é basicamente um sistema de indicadores para gestão ambiental de atividades rurais. Consiste de um conjunto de plataforma (MS-Excel) que integra 62 indicadores de desempenho, em cinco dimensões de sustentabilidade analisadas na escala de estabelecimentos rurais: 1) ecologia da paisagem, 2) qualidade ambiental (atmosfera, água e solo), 3) valores socioculturais, 4) valores econômicos 5) gestão e administração (Stachetti, 2003). Dessa forma, permite melhorar a gestão ambiental de atividades do meio rural, indicando os pontos críticos para correção do manejo, bem como os aspectos favoráveis das atividades, para o desenvolvimento sustentável (Rodrigues e Campanhola, 2003; Rodrigues et al, 2010).

A aplicação do método APOIA-NovoRural consistiu na identificação dos limites espaço-temporais da atividade avaliada, no âmbito do estabelecimento rural, vistoria em campo, coleta de dados, análise de solo e água, levantamento de informações gerenciais junto ao produtor/administrador. Posteriormente, foi realizada a inserção dos dados nas matrizes de ponderação do sistema, obtendo os índices de impacto referentes aos indicadores, que foram convertidos automaticamente para valores de utilidade na escala de 0 a 1 . De acordo com Girardin et al. (1999), o valor da linha de base $(0,70)$ correspondeu a um efeito que implica estabilidade no desempenho ambiental da atividade.

O método do APOIA Novo Rural, fez um comparativo do antes e depois de um tempo, pois se baseia em uma curva de tendências que só pode ser mensurada se fixado o período de avaliação. Dessa forma, foi utilizado uma data de avaliação inicial anterior as atividades produtivas, e uma data após intervenções, depois do início da produção. Para o diagnóstico apresentado neste trabalho foi usada a data de início de janeiro de 2014 e a data final em setembro de 2016. O trabalho foi elaborado em três etapas, na primeira foi realizado o diagnóstico da propriedade. A segunda etapa constituiu na análise dos resultados e a última etapa nos planos de melhoria baseados nos resultados das etapas anteriores.

O APOIA-NovoRural é completo quando se trata das dimensões ambiental e social. Dessa forma, durante o diagnóstico realizado foram coletados dados sociais, ambientais e econômicos, além de visitas à propriedade para o processo de obtenção de dados com colaboradores, gestores e proprietários. Após a coleta de dados, estes foram inseridos no programa, o detalhamento de cada dimensão da sustentabilidade está apresentado a seguir:

Para a dimensão de ecologia da paisagem foram usados dados obtidos em campo e em mapas gerados por empresa de georreferenciamento para confecção do Cadastro Ambiental Rural [CAR]. No campo foram entrevistados os responsáveis pela administração e os proprietários da fazenda. As subdimensões avaliadas foram: 1) Fisionomia e conservação dos habitats naturais: os dados foram coletados em mapas detalhados com as áreas de preservação permanente, de reserva legal, de vegetação florestal remanescente, de pastagem nativa, de pastagem implantada, de lagoas e de benfeitorias. 2) Diversidade e condições de manejo das áreas de produção: foi incluído que no programa que a produção da propriedade era predominantemente de pastagem plantada. 3) Diversidade e condições de manejo das atividades confinadas: foi inserido na base de dados que cerca de $95 \%$ da renda da propriedade vem da pecuária de corte, uma pequena parte provem da venda de animais para recria. 4) Cumprimento com requerimento da reserva legal: para realização da análise foi observado que a área averbada como reserva legal representa $21 \%$ da área total da propriedade, acima da

${ }^{1}$ Pereira, C.H. 2015. Simulação da sustentabilidade econômica e ambiental em três sistemas de produção de bovinos de corte no RS. Tese de Doutorado em Agronomia. Universidade Federal do Rio Grande do Sul, Porto Alegre, RS, Brasil. 
requerida pela legislação de 20\%. 5) Cumprimento com requerimento de áreas de preservação permanente: a área de $9 \%$ da propriedade é de área de preservação permanente [APP], que foi mantida intacta no período de 2014 a 2016. 6) Corredores de fauna: foram identificadas as áreas de habitats naturais, corredores de fauna e o número de fragmentos destas áreas, sendo todos mantidos nas mesmas quantidades durante todo o período analisado. 7) Regeneração de áreas degradadas: foram identificadas áreas de pastagem degradadas. Durante o período de 2014-2016 parte destas áreas degradadas foram formadas com pastagens novas visando a intensificação da pecuária. 8 ) Incidência de focos de doenças endêmicas: a propriedade não apresentou dados significativos de vetores de doenças endêmicas. 9) Risco de extinção de espécies ameaçadas: nenhuma das espécies presentes nas APP e áreas de reserva foram consideradas ameaçadas. 10) Risco de incêndio: basicamente os procedimentos de eliminação de uso intencional de fogo e o combate de incêndios não intencionais implantados reduziram a área atingida pelo risco. 11) Risco geotécnico: foi identificada apenas uma área de risco de assoreamento, nesta área foram implantadas medidas de contenção como barragens e cercas para evitar que animais pastoreiem ou aumentem o assoreamento.

$\mathrm{Na}$ análise da qualidade ambiental (atmosfera, água e solo) os procedimentos para avaliação foram: 1) Atmosfera: foi realizada uma avaliação pelo agrônomo considerando suspensão/fumaça, odores e índice de ruídos. 2) Água: foi realizada análise visual das águas superficiais e análise química e biológica a jusante e a montante de córregos que cruzam a propriedade. 3) Solo: foram feitas análises de solo em laboratório em 2015 e 2016 avaliando os seguintes itens: matéria orgânica, pH, fósforo $(\mathrm{P})$ resina, potássio $(\mathrm{K})$ trocável, magnésio $(\mathrm{Mg})$ e cálcio $(\mathrm{Ca})$ trocável, acidez potencial $(\mathrm{H}+\mathrm{Al})$, soma de bases, capacidade de troca catiônica, doma de bases em porcentagem de saturação.

As avaliações de valores socioculturais foram coletadas com colaboradores do departamento de recursos humanos, com o gerente geral e com os proprietários. Foram avaliados aspectos relacionados ao acesso à educação, a serviços básicos, aos padrões de consumo, de esporte e de lazer, vvva conservação do patrimônio histórico, artístico, arqueológico e espeleológico, a qualidade do emprego, a segurança e a saúde ocupacional e a oportunidade de emprego local qualificado.

Para análise dos valores econômicos, foram avaliados dados do departamento financeiro/contábil e informações repassadas pelo gerente geral e pelos proprietários. Foram abordadas perguntas relativas a renda líquida do estabelecimento, diversidade de fontes de renda, nível de endividamento corrente, valor da propriedade e qualidade da moradia. Os itens gestão e administração foram repassados pelo gerente geral, pelo agrônomo e pelos proprietários. Além disso, foi solicitado informações de um veterinário consultor da fazenda. Na propriedade estudada, o agrônomo é responsável pelas pastagens e o veterinário pelo controle animal, sanitário, manejo e genética. Os pontos avaliados foram dedicação e perfil do responsável, condição de comercialização, reciclagem de resíduos e relacionamento institucional.

$\mathrm{Na}$ segunda etapa, foram realizadas análises detalhadas dos resultados do programa APOIANovoRural. Desse modo, obteve-se um índice geral da contribuição da atividade para a sustentabilidade do estabelecimento rural. $\mathrm{Na}$ análise dos resultados apresentados nas planilhas, foram identificados os indicadores que restringem a sustentabilidade na propriedade. Dos índices com possíveis desconformidades com a linha de base $(0,7$ de índice médio), foram escolhidos 3 indicadores para aplicação de medidas corretivas, recomendações de adequação tecnológica, manejo para abatimento dos impactos ambientais negativos, bem como discutida a viabilidade de implantação de melhorias nestes pontos.

$\mathrm{Na}$ terceira e última etapa foram desenvolvidos planos e roteiros dos pontos a serem melhorados. A geração dos planos PDCA (Figura 1) para cada ponto de melhoria realizada com base na segunda etapa. Os planos PDCA usaram o método: 1) Planejar ("Plan"), 2) Desenvolver ("Do"): 3) Conferir (“Check") e 4) Atuar ("Action") (Basu, 2004; Soković et al., 2009).
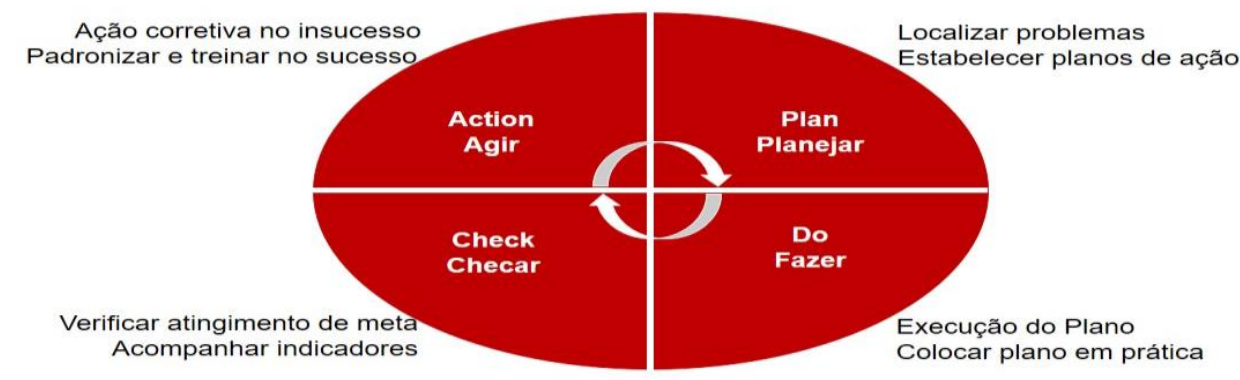

Figura 1. Roteiro de atividades do ciclo PDCA

Fonte: Adaptado de Campos (2004) 
Na busca de melhoria continua, quando uma passagem pelo ciclo PDCA (Figura 1) não resultar em melhora, o item ao qual o PDCA foi aplicado pode ser refinado com maiores detalhes na interação seguinte do ciclo, ou a atenção deve ser colocada de uma forma diferente em alguma fase do processo.

\section{Resultados e Discussão}

Os resultados gerais do diagnóstico da propriedade estão apresentados em blocos de indicadores (Figura 2, $3 \mathrm{~A}, 3 \mathrm{~B}, 4 \mathrm{~A}, \mathrm{AB}, 5,6$ e 7). As figuras representam as dimensões da sustentabilidade da propriedade. De modo geral, o desempenho da propriedade foi próximo do valor de referência 0,7 (Figura 2). A linha vermelha representa a base do índice $(0,7)$, que é considerada sustentável e a linha azul indica os resultados da propriedade em análise (Figura 2).
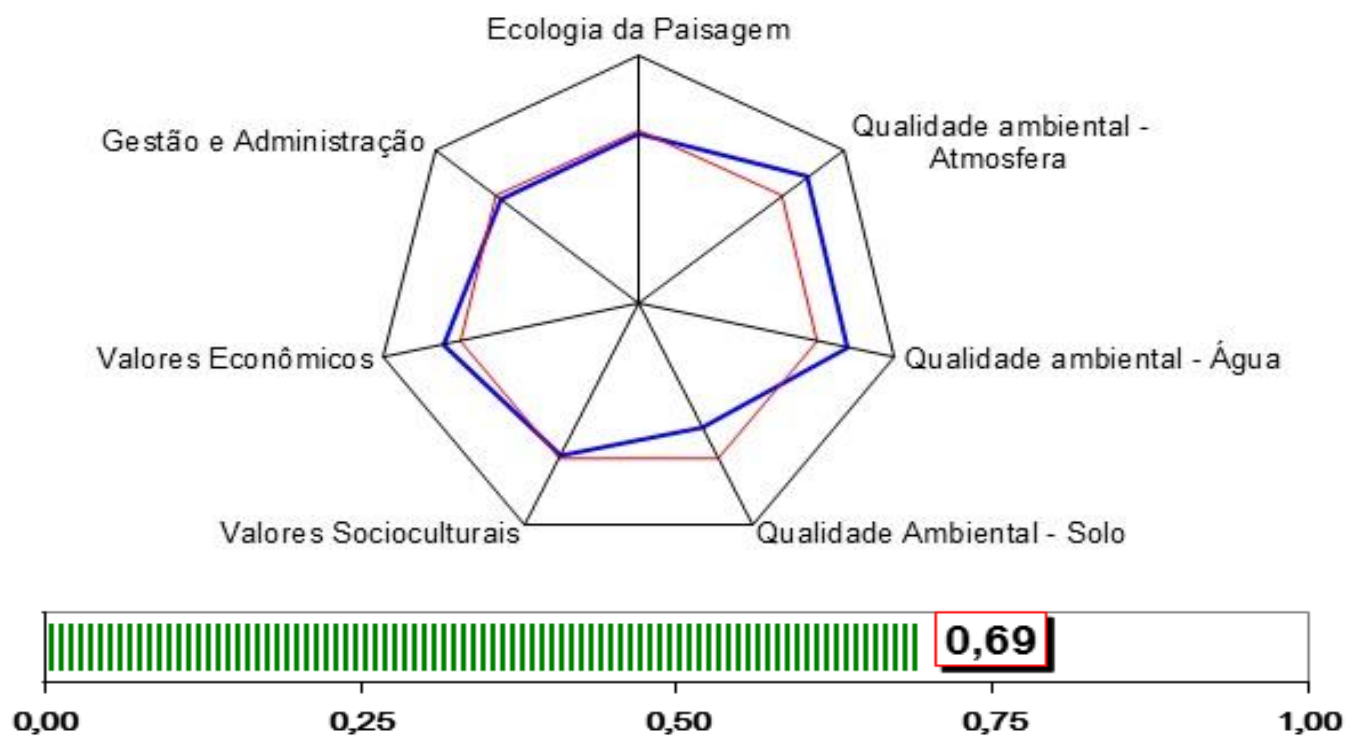

Figura 2. Desempenho ambiental das dimensões de avaliação e índice de sustentabilidade do estabelecimento

Em relação a análise ambiental, foi constatado níveis de partículas de fumaça baixos devido aos raros casos de incêndios (Figura 3A). Os odores foram considerados normais de uma propriedade de pecuária (Figura 3A). Também foi detectado baixo índice de ruídos, referentes a algumas máquinas de preparo de solo, roçadeiras e adubações. A análise da qualidade ambiental do solo indicou necessidade de correção
(Figura 3B). A qualidade da água foi considerada adequada, e o impacto potencial de pesticidas foi avaliado como baixo devido ao pouco uso dos mesmos nas pastagens. É válido ressaltar que todas as aplicações, realizadas na propriedade, foram controladas $e$ identificadas bem como as embalagens retornam ao fabricante. 
(A)

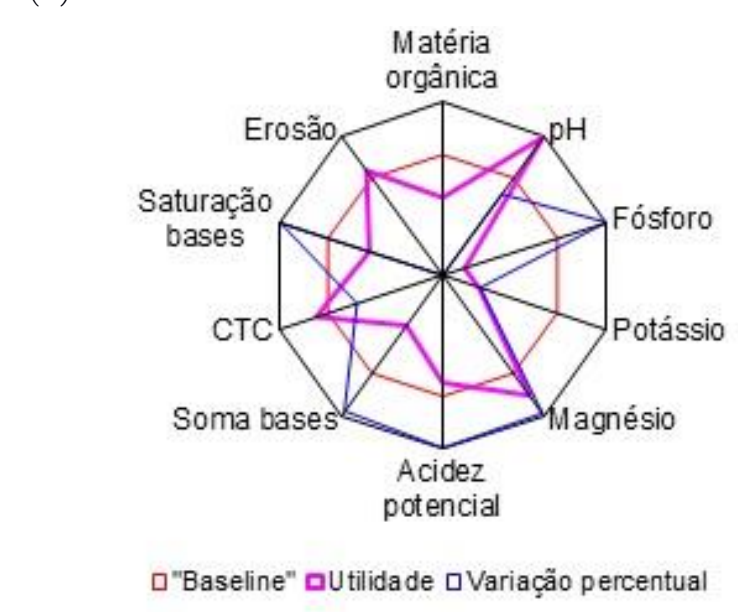

(B)

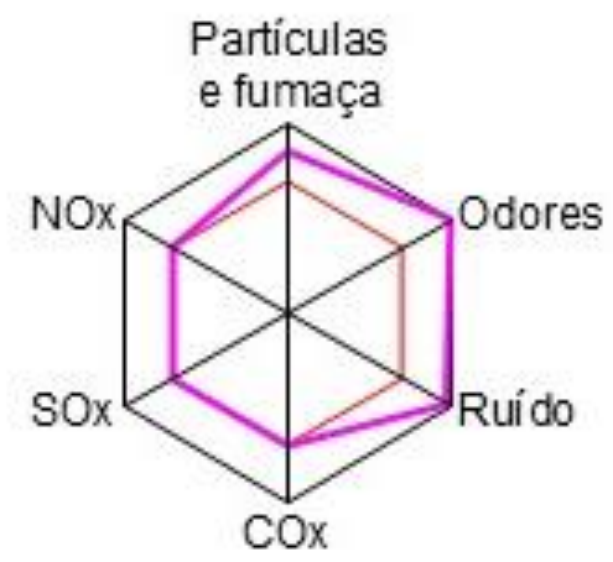

Figura 3. (A) Valores de utilidade dos indicadores de qualidade ambiental da atmosfera e (B) valores de qualidade ambiental do solo

Nota: NOx:Nitratos, SOx: Sulfatos, Cox: Carbonos, CTC: Capacidade de Troca de Cátions, pH: Medida de acidez

Em relação a análise econômica, foi observado que o APOIA-NovoRural propiciou apenas uma avalição superficial, apontando de forma qualitativa os pontos a serem melhorados (Figura 4A e 4B). Esse indicador é de extrema importância na propriedade, pois baseado no

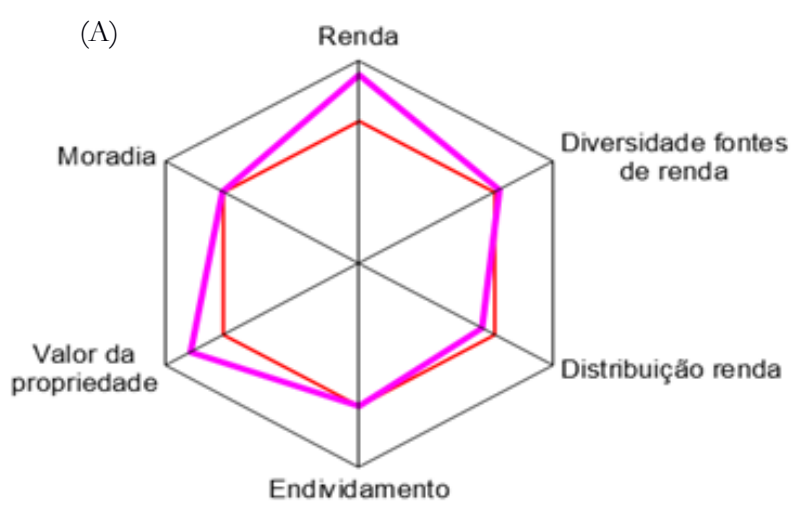

mesmo os gestores podem realizar tomada de decisões assertivas (Marion; Santos, 1993), imprescindíveis para uma pecuária de corte sustentável, econômica, social e financeiramente (Carvalho; De Zen, 2017).

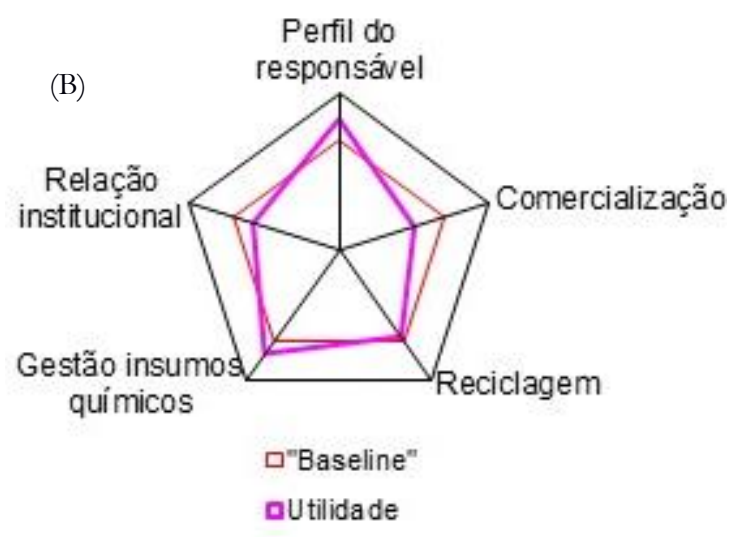

Figura 4. (A) Valores de utilidade dos indicadores de valores econômicos e (B) valores de gestão e administração

Após a avaliação dos indicadores da propriedade a diversidade produtiva, diversidade de paisagem e saúde ocupacional dos colaboradores foram identificados como pontos fracos. Após a definição esses índices foram utilizados como base para elaboração dos planos de melhoria utilizando o método PDCA (Figura 5). 


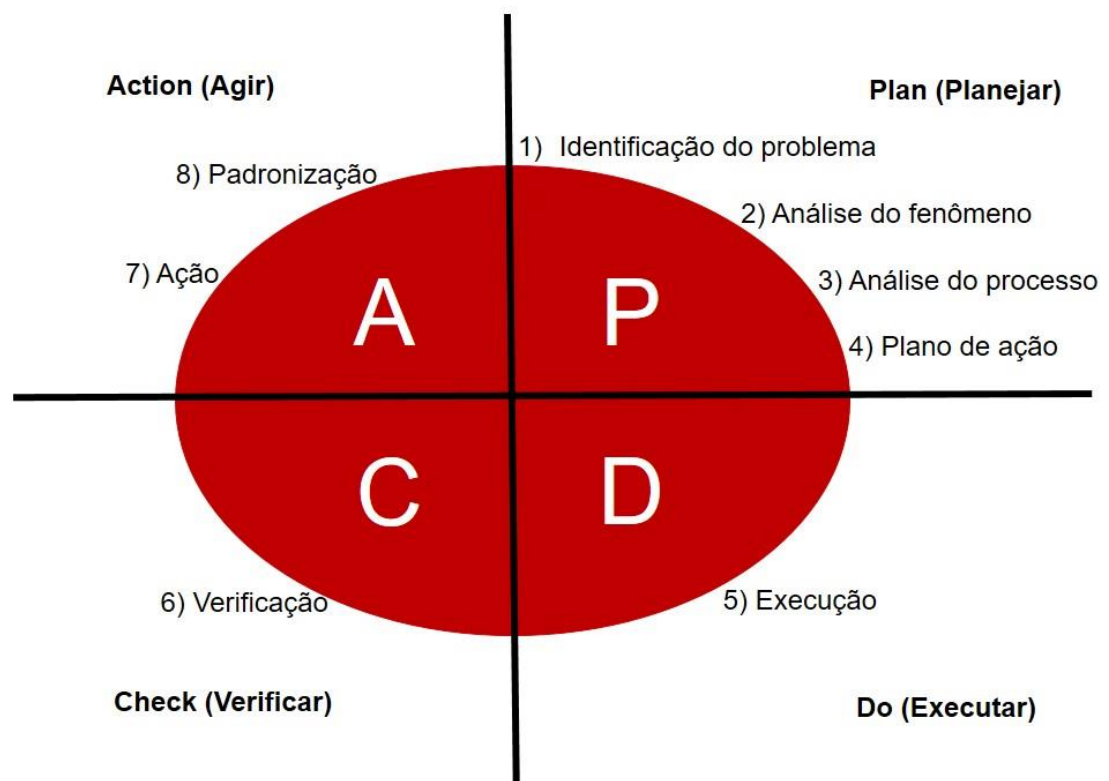

Figura 5. Detalhamento das tarefas do plano PDCA

Fonte: Adaptado de Campos (2004)

Dos três indicadores selecionados (Figura 6 e 7), a diversidade produtiva $(0,00)$ foi o principal item de preocupação, pois impacta diretamente na geração de renda, isso se deve ao fato da atividade predominante ser a pecuária de corte. Para este indicador foi apresentado plano com o intuito de aumentar as possíveis fontes de renda da propriedade. O segundo indicador destacado foi a diversidade de paisagem $(0,02)$. O bioma predominante é o cerrado, o que pode dificultar a implementação de diversidade neste caso, pois pode-se causar um dano maior ao ambiente ao inserir outras espécies de cultivares ou florestas estrangeiras ao cerrado. O terceiro indicador de melhoria foi a saúde ocupacional dos colaboradores $(0,21)$, visto que não existe um plano de saúde oferecido aos colaboradores, somente a rede pública de saúde está disponível.

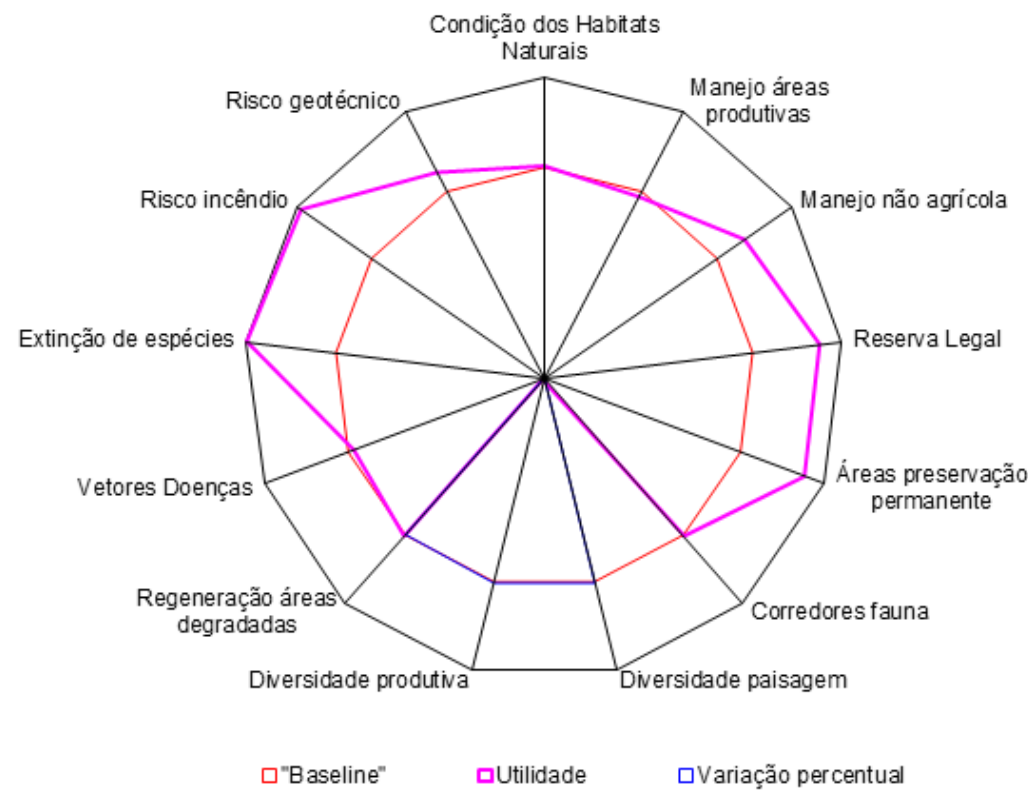

Figura 6. Valores de utilidade dos indicadores de ecologia da paisagem 


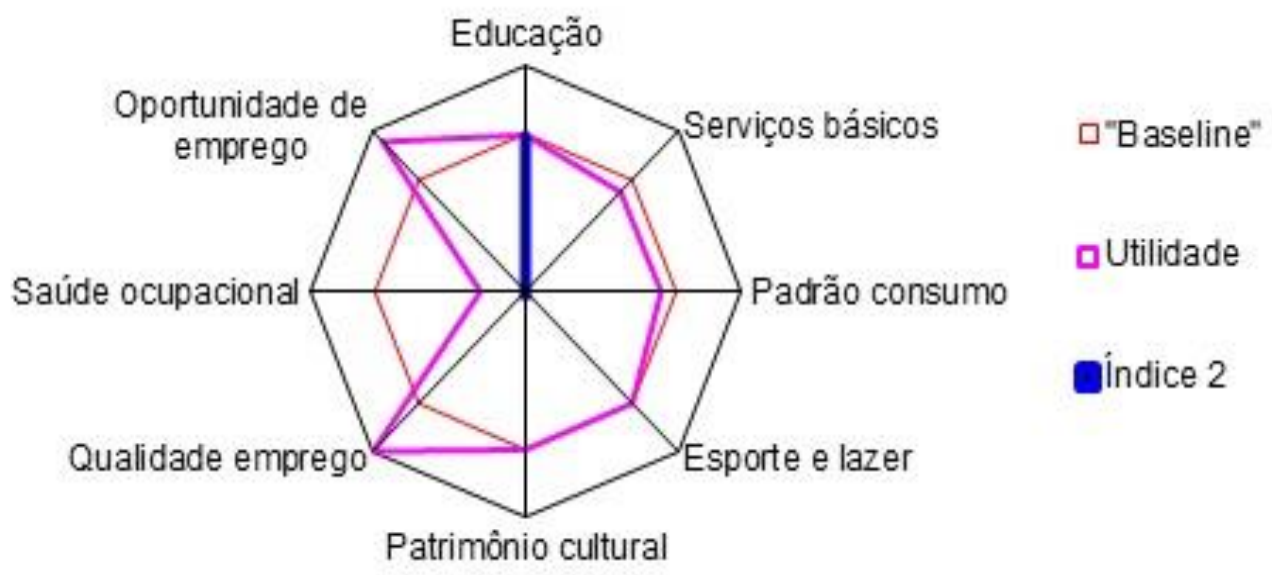

Figura 7. Valores de utilidade dos indicadores de valores socioculturais

O plano de melhoria da diversidade produtiva e de paisagem pode proporcionar aumento das fontes de renda e a diversidade de paisagem. Existem vários sistemas de produção destinados a agropecuária que tem como objetivo aumentar a diversidade produtiva da propriedade, a Integração Lavoura Pecuária e Floresta [ILPF], a Integração Lavoura Pecuária [ILP] e o sistema silvipastoril. O plano proposto para a propriedade estudada foi o sistema silvipastoril, pois o mesmo desenvolve a pecuária integrada a floresta, aumentando $\mathrm{o}$ índice de diversidade tanto econômica como da paisagem (Silva, 2010), impacta positivamente na capacidade produtiva do solo seguido do indicador de biodiversidade (Silva, 2012) ${ }^{2}$.

A diversificação de produção proporciona uma gama de opções de mercado, tornando-se um ponto chave ao produtor rural contra possíveis crises econômicas. Outros benefícios do sistema silvipastoril são as árvores, pois ao proporcionar sombra, quebra-vento e abrigo, diminuem o estresse climático, gerando aumento na produção animal. A distribuição de árvores na pastagem também reduz a erosão, melhora a conservação de rios, córregos e nascentes (Santos e Grzebieluckas, 2014). As principais atividades relacionadas a ações do plano PDCA do sistema silvipastoril, proposto para ser implementado na propriedade oriunda desse estudo estão apresentadas na figura 8.

Em relação ao planejamento (Figura 8), na análise do processo detalhada com os indicadores das planilhas, o plano de ação baseou-se em uma definição do escopo, dos recursos e um cronograma de execução. $\mathrm{Na}$ implantação do sistema silvipastoril em parte da propriedade foi realizado a definição de um local e área a ser implantada. Para escolha do local adequado levouse em consideração o manejo dos animais, qualidade do solo, disponibilidade de água, insolação e orientações dos plantios. Na escolha das árvores adequadas considerouse a finalidade para o uso da madeira (serraria, laminação, cercas, palanques ou carvão). Outro fator importante a ser levado em conta foi como a disposição das árvores interferiu na conservação do solo e da água (Silva, 2010). Para implementação desse plano foi proposto o uso dos recursos humanos existentes na propriedade. Os equipamentos, adquiridos com recursos financeiros próprios, devem ser comprados para plantio de árvores, controle de pragas, desbaste e corte de árvores. Em relação a pecuária devem ser elaborados projetos de manejo, indicando os tamanhos dos piquetes de pasto, as cercas, cochos e bebedouros.

Considerando as condições climáticas, será feito o cronograma de atividades ao longo do ano com os seguintes itens: delimitação das áreas (georreferenciamento): alocação de cercas, praça de alimentação, área para o plantio das árvores, alinhamento Leste-Oeste; compra ou aluguel de máquinas e implementos necessários ao plantio; preparo da terra, análise de solos, escolha dos cultivares de árvores e gramíneas, execução de aragem, gradeamento, curvas de nível e calagem; adubação antes do plantio; plantio das gramíneas; plantio das árvores; construção de cercas; construção de bebedouros e cochos; entrada dos animais, treinamento dos colaboradores para o correto manejo em sistema silvipastoril, controle de pragas, desbastes das árvores (em função do cultivar escolhido), adubação após plantio, análise de solo, manutenção da qualidade das pastagens.

2 Silva, A.A. 2012. Sistema Silvipastoril como alternativa de manejo sustentável de pastagem para produção de leite na Região Central do estado de Rondônia. Dissertação de Mestrado. Universidade Federal de Rondônia, Porto Velho, RO, Brasil. 


\begin{tabular}{|l|l|}
\hline \multicolumn{1}{|c|}{ PLAN } & \multicolumn{1}{c|}{ DO } \\
\hline Determinação da area a ser plantada & Treinamento dos colaboradores \\
\hline Que máquinas serão utilizadas & Preparação do Solo \\
\hline Definir colaboradores para plantio e manejo & Adubação \\
\hline Definição do tipo de árvore e gramínea & Pulverização \\
\hline Datas para plantio e entrada dos animais & Controle de pragas \\
\hline \hline \multicolumn{1}{|c|}{ CHECK } & \\
\hline Identificação dos erros operacionais no manejo & Melhoria do manejo \\
\hline Ações ambientais e climáticas & Melhoria das florestas \\
\hline Análise do desempenho das árvores & Correção de solo \\
\hline Análise de desempenho dos animais & \\
\hline Análise de solos & \\
\hline
\end{tabular}

Figura 8. Lista de ações do plano PDCA do sistema silvipastoril proposto para ser implementado na propriedade em que predomina o bioma cerrado

O plano de melhoria da saúde ocupacional visou melhorar o indicador de social relativo ao bem-estar dos colaboradores da propriedade. Foram identificadas as principais atividades relacionadas com a escolha de um plano de saúde, para os colaboradores da propriedade, estão apresentados na figura 9 .

\begin{tabular}{|l|l|}
\hline \multicolumn{1}{|c|}{ PLAN } & \multicolumn{1}{c|}{ DO } \\
\hline Consulta aos plano e seguros da região & Comunicação aos colaboradores \\
\hline Comparar os custos e qualidade & Apresentação do plano de saúde \\
\hline Número de vidas/dependentes & Adesão dos colaboradores e dependentes \\
\hline Datas para a implantação & \\
\hline Escolha do plano & \\
\hline \hline \multicolumn{1}{|c|}{ CHECK } & ACT \\
\hline Monitorar o uso do plano & Em função da satisfação exigir melhorias \\
\hline Fazer pesquisa de satisfação dos colaboradores & \\
\hline
\end{tabular}

Figura 9. Lista de ações do plano PDCA de saúde ocupacional proposto para ser implementado na propriedade em que predomina o bioma cerrado

A definição inicial do plano teve como objetivo principal de melhorar a saúde ocupacional dos colaboradores (Figura 9). Atualmente existe apenas o sistema único de saúde [SUS] público com poucos recursos para atender de forma adequada o pessoal. Após a identificação de um plano de saúde particular e que atenda aos interesses dos colaboradores e proprietários, o departamento de recursos humanos terá a função de incluir o benefício na folha de pagamento. $\mathrm{O}$ cronograma de implementação do plano de saúde compreende consulta aos planos de saúde da região, comparativo de custos e benefícios de cada um dos planos, modelos com ou sem coparticipação, levantamento do número de interessados e seus dependentes e escolha do plano e datas para implantação. Para implementar o plano de saúde será necessária a comunicação aos colaboradores da escolha, apresentação do plano escolhido e adesão do colaborador e seus dependentes.

No terceiro passo do ciclo ("Check"), podem ser detectados erros ou falhas a serem corrigidos. É necessário o monitoramento da qualidade dos serviços prestados pela seguradora e também a satisfação dos colaboradores com os serviços prestados. No quarto passo ("Action") caso o monitoramento indique mudanças no plano estas devem ser colocadas em prática nesta fase, garantindo assim um processo de melhoria contínua. 


\section{Conclusões}

$\mathrm{Na}$ análise de sustentabilidade, realizada pelo programa APOIA-NovoRural, foi possível identificar que a diversidade produtiva, diversidade de paisagem e saúde ocupacional eram pontos fracos na propriedade estudada. Após a identificação desses itens, foram elaborados ciclos PDCA para melhoria contínua do processo. Para os dois primeiros, um sistema silvipastoril foi proposto e detalhado em escopo, recursos e cronograma. Para o terceiro ponto foi proposta uma pesquisa de planos ou seguros de saúde na região. Com a implementação dos planos a serem desenvolvidos, possivelmente a propriedade obterá valores melhores e suficientes para ser considerada como propriedade sustentável.

Com o método padronizado a identificação e geração de melhorias pode ser utilizada novamente dentro da empresa, em outras propriedades, bem como em outras situações de melhoria. Assim, com métricas sendo usadas de forma sistemática, desenvolve-se uma condição básica para a melhoria contínua dos processos de produção da fazenda.

\section{Referências}

Alves, F.V.; Almeida, R.G.; Laura, V.A. 2015. Carne Carbono Neutro: um novo conceito para a carne sustentável produzida nos trópicos (Documentos 210). Embrapa Gado de Corte, Brasília, DF, Brasil.

Basu, R. 2004. Implementing Quality - A Practical Guide to Tools and Techniques, Thomson Learning, London.

Campos, V. F. 2004. Controle da Qualidade Total (no estilo japonês). $8^{a}$ edição. INDG Tecnologia e Serviço, Nova Lima, MG, Brasil.

Carvalho, T. B. de; De Zen, S. 2017. A cadeia de Pecuária de Corte no Brasil: evolução e tendências. Revista iPecege 3(1):85-99.

Girardin, P.; Bockstaller, C.; Van Der Werf, H. 1999. Indicators: tools to evaluate the environmental impacts of farming systems. Journal of Sustainable Agriculture 13 (4): 5-21.

Instituto Brasileiro de Geografia e Estatística [IBGE]. 2013. Produção da Pecuária Municipal. Prod. Rio de Janeiro: IBGE. 41: 1-108.

Kuzma, E. L.; Doliveira, S. L. D.; Atamanczuk, M. J.; Cardoso, A.A. 2015. O Perfil Financeiro das empresas Aderentes e Não Aderentes ao Índice de Sustentabilidade Empresarial da BM\&FBOVESPA. Organizações e Sustentabilidade, 3 (1): 47-78.

Marion, J.C.; Santos, G. J. dos 1993. Administração de Custos na Agropecuária. Atlas, São Paulo, SP, Brasil.

Ministério da Ciência, Tecnologia e Inovação [MCTI]. 2010. Segunda Comunicação Nacional do Brasil à convenção-Quadro das Nações Unidas sobre Mudança do Clima. Brasília, DF, Brasil.
Peters, T. 1998. O círculo da inovação. Harbra, São Paulo, SP, Brasil.

Silva, V.P. da. 2010. Arborização de pastagens com espécies florestais madeireiras: implantação e manejo. Embrapa Florestas, Colombo, PR, Brasil.

Rodrigues, G.S.; Campanhola, C. 2003. Sistema integrado de avaliação de impacto ambiental aplicado a atividades do novo rural. Pesquisa Agropecuária Brasileira, Brasília 38 (4): 445-451.

Rodrigues, G.S.; Rodrigues, I.A.; Buschinelli, C.C.A.; Barros, I. 2010. Integrated farm sustainability assessment for the environmental management of rural activities. Environmental Impact Assessment Review 30 (4): 229-239.

Santos, S. da S.; Grzebieluckas, C. 2014. Sistema silvipastoril com eucalipto e pecuária de corte: uma análise de viabilidade econômica em uma propriedade rural em Mato Grosso/Brasil. Custos e @gronegócio 10 (3): 317-333.

Simões, A.R.P.; Moura, A.D. 2006. Análise de risco do desempenho econômico de um sistema de recria de gado de corte em regime de pastejo rotacionado. Revista de Economia e Agronegócio 4 (1): 75-98.

Soković, M; Jovanović, J; Krivokapić, Z.; Vujović, A. 2009. Basic Quality Tools in Continuous Improvement Process. Journal of Mechanical Engineering 55 (5): 1-9.

Stachetti, G.R. 2003. Avaliação de impacto de atividades em estabelecimentos familiares do novo rural. Embrapa Meio Ambiente, Jaguariúna, SP, Brasil. 